\title{
ALLERGIES IN INDIA- A STUDY OF 6270 PATIENTS
}

\author{
Wiqar A. Shaikh', Shifa Wiqar Shaikh²
}

${ }_{1}^{1}$ Allergist and Asthmologist, Department of Clinical Allergy, Allergy and Asthma Clinic, Mumbai, Maharashtra, India. ${ }^{2}$ Allergist and Asthmologist, Department of Clinical Allergy, Allergy and Asthma Clinic, Mumbai, Maharashtra, India.

\section{ABSTRACT}

\section{BACKGROUND}

Allergies afflict a large population of the world. Previous studies have revealed that the incidence of allergic manifestations and causative allergens in India are different from the western countries.

\section{MATERIALS AND METHODS}

6270 consecutive patients with allergic manifestations attending the clinic from July 01, 2008 to June 30, 2018 were included in this study. Patients underwent a complete allergy work-up including total serum IgE levels, skin prick tests, patch tests, pulmonary function tests and nasal function test.

\section{RESULTS}

The results obtained from this study revealed that atopy is less common in India as compared to the west. Pollen allergy and food allergy are also less common in India. Cocoa is the commonest food allergen in India and insect allergens have a high positivity rate.

\section{CONCLUSION}

Allergies in India are different from the west. We are justified in coining the term "Tropical Allergy and Asthma" as a different clinical entity when compared with allergies in western countries.

\section{KEY WORDS}

Allergy, Asthma, Atopy, Conjunctivitis, Contact Dermatitis, Eczema, Rhinitis, Urticaria

HOW TO CITE THIS ARTICLE: Shaikh WA, Shaikh SW. Allergies in India- a study of 6270 patients. J. Evolution Med. Dent. Sci. 2019;8(10):657-661, DOI: 10.14260/jemds/2019/146

\section{BACKGROUND}

Allergies (Atopic diseases) are the commonest of diseases afflicting mankind. There have been studies in the past which have reported the incidence of various allergies in India (1-4) and a previous study showed an incidence of approximately $29 \%$ atopy in the Indian population.(4) However, the last study is more than a decade old.(4) The present study was therefore designed to determine the current incidence of atopy, the incidence and age distribution of allergic manifestations, total serum IgE levels and the positivity rates for various allergens on skin prick testing (SPT). This study also provides an insight into the pattern of distribution of allergic diseases in the paediatric age group in India. Yet another aim of this study was to analyse the changes in the pattern of allergens and allergic diseases in India when compared with previous studies and with western countries.

\section{MATERIALS AND METHODS}

The descriptive study of 6270 consecutive patients attending the clinic from from July 01, 2008 to June 30, 2018, were included. Patients who attended the clinic for

'Financial or Other Competing Interest': None.

Submission 17-01-2019, Peer Review 22-02-2019,

Acceptance 26-02-2019, Published 11-03-2019.

Corresponding Author:

Dr. Wiqar A. Shaikh,

Allergy and Asthma Clinic,

Shakti Sadan, Lamington Road,

Mumbai-400007,

Maharashtra, India.

E-mail:drwiqar@gmail.com

DOI: $10.14260 /$ jemds/2019/146 complaints other than allergies were excluded. The manifestations warranting inclusion were asthma, rhinitis, urticaria/angioedema, atopic dermatitis, contact dermatitis, allergic conjunctivitis and drug allergies.

\section{Each Patient Underwent the Following-}

1. A detailed history followed by a physical examination.

2. Estimation of total serum IgE levels using the ELISA method (normal values were 0 to $50 \mathrm{IU} / \mathrm{ml}$ ). However, patients having contact dermatitis did not undergo IgE level estimation.

3. Skin prick test (SPT) using a battery of 90 common, Indian allergens.

4. Patients having contact dermatitis underwent "patch tests" with commercially available patch test allergens.

5. Patients having asthma underwent spirometry using a computerised spirometer and those with rhinitis underwent "peak nasal inspiratory flow rate" (PNIFR) using a Youlten peak nasal inspiratory flow meter. However, spirometry and PNIFR have not been analysed in this study.

6. To determine the incidence of atopy in India, 1000 random volunteers underwent SPT with 6 common allergens in India, viz. house dust mite (D. farinae), mosquito, house fly, cockroach, cat and dog. One or more positive reaction was taken as the criteria to label a volunteer as "atopic".

\section{RESULTS}

The results of this study are tabulated in Tables 1 to 9 . 


\begin{tabular}{|c|c|c|c|c|c|c|}
\hline Age Groups & \multicolumn{2}{|c|}{ Male } & \multicolumn{2}{|c|}{ Female } & \multicolumn{2}{|c|}{ Total } \\
\hline Years & Number & $\%$ & Number & $\%$ & Number & $\%$ \\
\hline $6-12$ & 396 & 11.56 & 174 & 6.12 & 570 & 9.09 \\
\hline $13-20$ & 444 & 12.96 & 456 & 16.03 & 900 & 14.35 \\
\hline $21-30$ & 798 & 23.29 & 690 & 24.26 & 1488 & 23.73 \\
\hline $31-40$ & 786 & 22.94 & 726 & 25.53 & 1512 & 24.12 \\
\hline $41-50$ & 528 & 15.41 & 456 & 16.03 & 984 & 15.69 \\
\hline $51-60$ & 348 & 10.16 & 264 & 9.28 & 612 & 9.76 \\
\hline 61 and Above & 126 & 3.67 & 78 & 2.74 & 204 & 3.25 \\
\hline Total & 3426 & 54.4 & 2844 & 45.36 & 6270 & 100 \\
\hline
\end{tabular}

\begin{tabular}{|c|c|c|c|}
\hline Sex & Children & Adults & Total \\
\hline Males & $39669.47 \%$ & $303053.16 \%$ & $342654.64 \%$ \\
Females & $17430.53 \%$ & $267046.84 \%$ & $284445.36 \%$ \\
\hline Total & $5709.09 \%$ of Total & $570090.91 \%$ of Total & 6270 \\
\hline \multicolumn{2}{|r|}{ Table 2. Sex Distribution } \\
\hline
\end{tabular}

\begin{tabular}{|c|c|c|c|c|c|c|c|c|c|c|}
\hline \multirow[b]{2}{*}{$\dot{z}^{\circ}$} & \multirow[b]{2}{*}{ 总 } & \multicolumn{3}{|c|}{ Children } & \multicolumn{3}{|c|}{ Adults } & \multicolumn{3}{|c|}{ Total } \\
\hline & & 泀 & 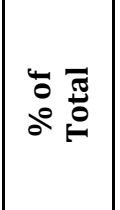 & 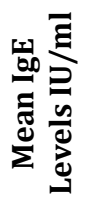 & 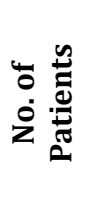 & 苂 & 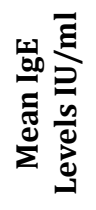 & 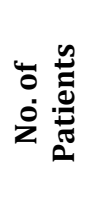 & 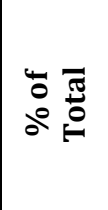 & 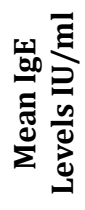 \\
\hline 1. & Asthma + Rhinitis \pm Conjunctivitis & 251 & $44 \%$ & 1802 & 2022 & $35.47 \%$ & 1689 & 2273 & $36.3 \%$ & 1702 \\
\hline 2. & Rhinitis \pm Conjunctivitis & 55 & $9.65 \%$ & 1740 & 1184 & $20.77 \%$ & 1494 & 1239 & $19.8 \%$ & 1505 \\
\hline 3. & Asthma & 23 & $4.1 \%$ & 1761 & 1409 & $24.7 \%$ & 1527 & 1432 & $21.4 \%$ & 1526 \\
\hline 4. & Urticaria & 67 & $11.7 \%$ & 1259 & 592 & $10.4 \%$ & 1341 & 659 & $10.5 \%$ & 1333 \\
\hline 5. & Contact Dermatitis & 17 & $2.98 \%$ & - & 175 & $3.07 \%$ & - & 192 & $3.1 \%$ & - \\
\hline 6. & Conjunctivitis & 8 & $1.4 \%$ & 887 & 30 & $0.53 \%$ & 832 & 38 & $0.61 \%$ & 844 \\
\hline 7. & Drug Allergies & 22 & $3.86 \%$ & 789 & 175 & $3.07 \%$ & 762 & 197 & $3.14 \%$ & 765 \\
\hline 8. & Atopic Dermatitis & 127 & $22.28 \%$ & 1923 & 113 & $1.98 \%$ & 1811 & 240 & $3.83 \%$ & 1870 \\
\hline & Total & 570 & $9.09 \%$ & - & 5700 & $90.91 \%$ & - & 6270 & $100 \%$ & - \\
\hline
\end{tabular}

\begin{tabular}{|c|c|c|c|c|}
\hline \multirow{2}{*}{ No. } & \multirow{2}{*}{ Allergen Groups } & Children & Adults & Total \\
\cline { 2 - 4 } & & $6.45 \%$ & $6.90 \%$ & $6.82 \%$ \\
2. & Pollen & $31.43 \%$ & $32.26 \%$ & $31.53 \%$ \\
3. & Fungi & $65.96 \%$ & $66.82 \%$ & $66.66 \%$ \\
4. & Insects & $72.08 \%$ & $74.15 \%$ & $73.25 \%$ \\
5. & Dust mites & $48.74 \%$ & $51.48 \%$ & $49.11 \%$ \\
6. & Dusts & $35.66 \%$ & $43.51 \%$ & $39.56 \%$ \\
7. & Danders/Fabrics & $8.98 \%$ & $11.30 \%$ & $9.25 \%$ \\
\hline
\end{tabular}

Table 4. Skin Prick Test Positive Percentage for Various Allergen Groups

Skin Prick Tests were Performed in 6078 out of 6270 Patients (5525 Adults and 553 Children)

\begin{tabular}{|c|c|c|c|}
\hline \multirow{2}{*}{ Allergens } & \multicolumn{2}{|c|}{ \% Positive } & Total \\
\cline { 2 - 4 } & Children & Adults & 11.17 \\
A. Pollen & 7.69 & 11.52 & 13.56 \\
1. Parthenium hysterophorus & 8.42 & 14.08 & 11.09 \\
2. Zea mays & 12.10 & 10.98 & 3.29 \\
3. Cynodon dactylon & 4.66 & 3.15 & 39.78 \\
4. Cocos nucifera & & & 30.59 \\
B. Fungi & 35.49 & 40.21 & 31.74 \\
1. Cladosporium herbarum & 27.33 & 30.92 & 35.34 \\
2. Curvularia spinosus & 27.43 & 32.16 & 35.52 \\
3. Alternaria tenius & 30.79 & 35.80 & 36.13 \\
4. Aspergillus fumigatus & 29.44 & & \\
5. Mucor mucedo & & & \\
\hline
\end{tabular}




\begin{tabular}{|c|c|c|c|}
\hline $\begin{array}{l}\text { C. Insects } \\
\text { 1. Moth } \\
\text { 2. Mosquito } \\
\text { 3. House fly } \\
\text { 4. Cockroach }\end{array}$ & $\begin{array}{l}71.69 \\
75.52 \\
71.11 \\
63.23\end{array}$ & $\begin{array}{l}77.08 \\
79.45 \\
74.77 \\
68.59\end{array}$ & $\begin{array}{l}76.60 \\
78.76 \\
74.43 \\
68.12\end{array}$ \\
\hline $\begin{array}{c}\text { D. Dust Mites } \\
\text { 1. D. farinae } \\
\text { 2. D. pteronyssinus }\end{array}$ & $\begin{array}{l}81.75 \\
69.91\end{array}$ & $\begin{array}{l}83.39 \\
65.12\end{array}$ & $\begin{array}{l}83.24 \\
65.15\end{array}$ \\
\hline $\begin{array}{l}\text { E. Danders } \\
\text { 1. Cat } \\
\text { 2. Dog }\end{array}$ & $\begin{array}{l}62.43 \\
60.61\end{array}$ & $\begin{array}{l}69.81 \\
65.27\end{array}$ & $\begin{array}{l}69.14 \\
64.84\end{array}$ \\
\hline $\begin{array}{l}\text { F. Foods } \\
\text { 1. Cocoa / Chocolate } \\
\text { 2. Cashew nuts } \\
\text { 3. Coconut } \\
\text { 4. Prawns } \\
\text { 5. Fish } \\
\text { 6. Crabs } \\
\text { 7. Groundnuts } \\
\text { 8. Mustard } \\
\text { 9. Legumes } \\
\text { 10. Soya bean } \\
\text { 11. Pineapple } \\
\text { 12. Peas } \\
\text { 13, Rice }\end{array}$ & $\begin{array}{c}29.98 \\
18.62 \\
15.45 \\
15.32 \\
15.30 \\
15.18 \\
12.21 \\
10.07 \\
7.23 \\
11.03 \\
10.44 \\
10.12 \\
0.58\end{array}$ & $\begin{array}{c}28.03 \\
16.96 \\
19.12 \\
14.18 \\
14.05 \\
14.01 \\
15.14 \\
16.59 \\
10.61 \\
13.96 \\
14.67 \\
14.28 \\
1.02\end{array}$ & $\begin{array}{c}28.21 \\
17.11 \\
18.78 \\
14.29 \\
14.17 \\
14.12 \\
14.88 \\
16.00 \\
10.30 \\
13.69 \\
14.29 \\
13.90 \\
0.98 \\
\end{array}$ \\
\hline $\begin{array}{c}\text { G. Dusts } \\
\text { 1. Cotton Dust } \\
\text { 2. House Dust }\end{array}$ & $\begin{array}{l}69.85 \\
60.11\end{array}$ & $\begin{array}{l}74.26 \\
66.93\end{array}$ & $\begin{array}{c}72.15 \\
62.2\end{array}$ \\
\hline
\end{tabular}

\begin{tabular}{|c|c|c|c|c|}
\hline No. & Drugs & Children & Adult & Total \\
\hline 1. & Sulfonamides & 8 & 20 & 28 \\
2. & Penicillin & 6 & 6 & 12 \\
3. & NSAID's & 18 & 148 & 166 \\
4. & (Aspirin, Ibuprofen, Analgin, etc.) Other Drugs & 4 & 10 & 14 \\
\hline \multicolumn{2}{|r|}{ Total Table 6.: Drugs Causing Allergic Reactions } \\
\hline
\end{tabular}

\begin{tabular}{|c|c|c|c|c|}
\hline No. & Manifestations & Children & Adults & Total \\
\hline 1. & Anaphylaxis & 0 & 12 & 12 \\
2. & 19 & 146 & 165 \\
3. & Skin Rash (Urticaria, Angioedema, Fixed Drug Rash, etc.) & 5 & 18 \\
4. & Rhinitis & 8 & 17 & 25 \\
\hline \multicolumn{2}{|c|}{ Tablhma } & $\mathbf{3 2}$ & $\mathbf{1 8 8}$ & $\mathbf{2 2 0}$ \\
\hline
\end{tabular}

\begin{tabular}{|c|c|c|c|c|}
\hline & Allergens & Children \% Positive & Adults \% Positive & Total \% Positive \\
\hline 1. & Nickel Sulphate & $16.23 \%$ & $45.71 \%$ & $43.16 \%$ \\
2. & Parthenium Hysterophorus & $13.5 \%$ & $24.57 \%$ & $22.14 \%$ \\
\hline \multicolumn{4}{|r|}{ Table 8. Positive Patch Test Allergens } \\
\hline
\end{tabular}

\begin{tabular}{|c|c|}
\hline 1. Total no. of volunteers undergoing SPT & 1045 \\
2. No. of allergens used & 30 \\
3. No. of volunteers showing one or more positive reactions to SPT \\
4. Incidence of atopy in India & $35.98 \%$ \\
\hline \multicolumn{2}{|c|}{ Table 9. Incidence of Atopy in Indian Population } \\
\hline
\end{tabular}

\section{DISCUSSION}

6270 patients were included in this study, of which 570 patients $(9.09 \%)$ were children (Up to 12 years of age) and 5700 patients $(90.91 \%)$ were adults (Tables 1 and 2). The overwhelming ratio in favour of adults in this study is possibly because the allergy clinic is conducted by physicians (And not by paediatricians). Of the 6270 patients, 3426
(54.64\%) were males and 2844 (45.36\%) were females. An interesting observation in this study, is that the male: female ratio in children is approximately $2 / 3^{\text {rd: }} 1 / 3^{\text {rd }}$, whereas it is almost 1: 1 in adults. It is therefore obvious that some male children presenting with allergic manifestations, may grow out of their allergies during their passage from childhood to adolescence and into adulthood. Several female children, 
however, who were asymptomatic during childhood or may have had subclinical disease, tend to manifest allergic symptoms while entering adulthood. During, adolescence, therefore, watch out for the female child in India, because she may manifest allergic symptoms. It is also interesting to note that children manifest a combination of asthma with rhinitis more often than their adult counterparts (44\%: 35\%).

$71.29 \%$ of patients included in this study belonged to the age group below 40 years (Table 1). This confirms that allergies affect mainly the younger population and particularly the most productive years of life, resulting in a huge loss to the society at large. $3.25 \%$ of patients were above 61 years of age, which proves that allergies are not common in the senior citizen group.

Total serum IgE levels were found to be elevated in every patient in this study, except in patients with contact dermatitis where IgE was not estimated (Table 3). IgE levels were found to be the highest in patients with atopic dermatitis, an observation that has been reported in earlier studies in India.(1-4) It is also important to emphasize that no adverse reactions (Major or minor) were encountered to SPT in any of the patients included in this study. It could therefore be concluded that SPT is an extremely safe diagnostic tool in the hands of a trained allergist.

The distribution pattern/percentage of various allergic disease remains almost unchanged in both children and adults when compared with earlier studies(1-4) (Table. 3). Undoubtedly, nasobronchial allergies viz. asthma and/or rhinitis are the commonest allergic manifestations. The incidence of atopic dermatitis is similar to that reported from western countries (5). Also, atopic dermatitis in India is overwhelmingly common in children (22.28\%) when compared to adults (3.83\%), a pattern also reported from western countries.

In western studies, pollen allergens have shown a positive percentage of up to $62 \% .6,7)$ However, the positivity rate (on SPT) for pollen in this study is $6.82 \%$, which is in fact less than that reported in earlier studies. This suggests that pollen allergy is less common in India as compared to western countries (Table 4). Parthenium hysterophorus is one of the commonest positive pollen allergen in India (11.17\%) (Table 5). This weed which is commonly known as "Congress grass" is not native to India. It was introduced into India accidentally through wheat supplies from the USA in the 1960s. Parthenium found a rather conducive, tropical environment for its growth and has, in fact, grown and spread throughout several parts of the country. Parthenium allergy is a common cause of asthma, rhinitis and airborne contact dermatitis. The last mentioned is a particularly widespread condition, presenting with a severely itchy dermatitis of exposed areas such as the face, neck, hands and feet, with especially the face presenting a ghost-like appearance. Parthenium allergy has been extensively studied in India.(8-11)

In India, the incidence of insect allergy is high with an overall positivity of $66.66 \%$. This shows an increasing trend when compared with earlier Indian studies.(1-4) The incidence of positivity to dust mites is also higher than earlier studies (73.25\%).(1-4) D. farinae is more common in India (83.24\%) as compared to D. pteronyssinus (65.15\%). Indeed, D. farinae has the highest positivity rate amongst all allergens commonly tested in India.
Food allergies are more common in India (9.25\%) as compared to other countries (3\%-7\%).(12) Amongst the food allergens, cocoa now has the highest positivity rate in India (28.21\%). Cashew nut, coconut, sea foods, peanut (groundnut), legumes (dals) and soya bean are the other common positive food allergens. Interestingly enough, the positivity rates for various allergen groups as well as for individual allergens were remarkably similar in both children and adults (Tables 4 and 5).

220 patients presented with drug allergies (Table 6). Of these, 206 patients reacted to the penicillin / cephalosporin group, sulphonamides and non-steroidal anti-inflammatory drugs (NSAIDs). Most drug allergies (165/200) presented with skin manifestations (urticaria, angioedema, fixed drug rash) (Table 7).

Patch test results reveal that nickel sulphate (43.16\%) and Parthenium hysterophorus (22.14\%) are the commonest culprit allergens (Table 8). Females wearing artificial jewellery and coin handlers have been found to have contact dermatitis to nickel.

The incidence of atopy in other countries has been found to be approximately $40 \% .{ }^{(13,14)}$ The present study concludes that the incidence of atopy in India is $35.98 \%$. When compared with earlier studies,(1-4) there has been a definite increase in the incidence of atopy in India from $25.3 \%$ in 1977 to $28.96 \%$ in $2007 / 2008$ to $35.98 \%$ in the present study.

A recently published study(15) has concluded that in India, allergies are heredofamilial diseases wherein son inherits the disease from the father and daughter from the mother.

There is enough evidence in this study to conclude that the pattern of allergic diseases in both children and adults and the allergens commonly seen in tropical India are different from those seen in the west. We are thus justified in coining the term "Tropical Allergy and Asthma" as a new subspecialty of allergy. $(16,17)$

\section{CONCLUSION}

1. Atopy is less common in India as compared to the western countries.

2. When compared with previous studies, the distribution pattern of various allergic disorders remains virtually unchanged in both children and adults.

3. In children, the male: female ratio is $2 / 3: 1 / 3$, whereas in adults it is almost $1: 1$. Indian females are therefore, more likely to grow into allergies as compared to their male counterparts, while growing out of childhood.

4. Pollen allergy is much less common in India as compared to western countries.

5. Food allergy is more common in India as compared to western countries.

6. The house dust mite D. farinae, has the highest positivity rate amongst all allergens in India.

7. There is a quantum increase in the incidence of allergy to cocoa and this is now the commonest food allergen in India.

8. More than two thirds of allergy sufferers in India are positive to insects (mosquito, house fly, cockroach, moth).

9. NSAIDs are the commonest cause of drug allergies in India and are responsible for more than $75 \%$ of all drug reactions. Again, more than $75 \%$ of drug reactions 
present with dermal manifestations (urticaria, angioedema, fixed drug reactions).

10. Allergies in India are different from the west. We are justified in coining the term "Tropical Allergy and Asthma" as a different clinical entity when compared with allergies in western countries.

\section{REFERENCES}

[1] Shaikh WA. Allergies in India: an analysis of 1619 patients attending and allergy clinic in Bombay, India. Int Rev Allergol Clin Immunol 1997;3:101-4.

[2] Shaikh WA. Allergies and Asthma in India: and analysis of 2467 patients seen over a six year period. Ind J Clin Pract 1998;8(12):23-6, 46-7.

[3] Shaikh WA. Allergies in children in India: an insight. Paed Pulmonol Update 1998;10:15-9.

[4] Shaikh WA, Shaikh SW. Allergies in India: an analysis of 3389 patients attending an allergy clinic in Mumbai, India. J Ind Med Assoc 2008;106(4):220-2, 4.

[5] Nutten S. Atopic dermatitis: global epidemiology and risk factors. Ann Nutr Metabol 2015;66(Suppl 1):8-16.

[6] Hendrick DJ, Davies RJ, D'Souza MF, et al. An analysis of skin prick test reactions in 656 asthmatic patients. Thorax 1975;30(1):2-8.

[7] Barbee RA, Lebowitz MD, Thomson HC, et al. Immediate skin-test activity in a general population sample. Ann Int Med 1976;84(2):129-33.

[8] Lonkar A, Mitchell JC, Calnan CD. Contact dermatitis from Parthenium hysterophorus. Trans St. John's Dermatol Soc 1974;60(1):43-53.
[9] Lonkar A, Nagasampagi BA, Narayanan CR, et al. An antigen from Parthenium hysterophorus. Contact Derm 1976;2(3):151-4.

[10] Rao M, Prakash O, Subba Rao PV. Reaginic allergy to Parthenium pollen: evaluation by skin test and RAST. Clin Allergy 1985;15(5):449-54.

[11] Grande G, Fernandes N. Parthenium allergy in Indian population. J Evid Based Med and Health Care 2015;2:7109-17.

[12] Loh W, Tang MLK. The epidemiology of food allergy in the global context. Int J Env Res Publ Health 2018;15(9):pii. E2043.

[13] Cockroft DW. Allergens. In: Barnes PJ, Drazen J, Rennard S, et al. eds. Asthma and COPD. $2^{\text {nd }}$ edn. Elsevier 2014: p. 443-5.

[14] Supakthanasiri P, Klaewsongkram J, Chauthaphakul H. Reactivity of allergy skin test in healthy volunteers. Singapore Med J 2014;55(1):34-6.

[15] Shaikh WA, Shaikh SW. Heredo - familial transmission of allergies in India - son inherits the disease from the father and daughter from the mother. Int J Med Sci Innov Res 2018;3(6):234-8.

[16] Shaikh WA. Allergy and Asthma - a tropical view. Delhi: IJCP Group of Publications and National Allergy and Asthma Campaign 2000.

[17] Singh AB, Dahiya P. Allergens in India-we are different from the West. In: Shaikh WA, edr. Principles and practice of tropical allergy and Asthma. Mumbai: Vikas Medical Publishers 2006: p. 61-91. 